\title{
Análise da Absorção de Água em Dois Polímeros Expandidos: Desenvolvimento do Módulo de Flutuabilidade de um Mini-robô Submarino
}

\author{
Nadège Bouchonneau, Adauto R. de Carvalho, Antônio R. L. de Macêdo \\ ARMTEC Tecnologia em Robótica
}

\author{
Lílian U. Viana, Adriana P. do Nascimento, João Batista F. Duarte, Antônio Roberto M. de Macêdo \\ Universidade de Fortaleza, UNIFOR
}

\begin{abstract}
Resumo: Polímeros expandidos são bastante competitivos para serem utilizados como materiais de flutuabilidade, devido a sua baixa densidade. Em particular, eles se apresentam muito eficientes no desenvolvimento de módulos de flutuabilidade de robôs submarinos do tipo ROV (Remote Operated Vehicle). Este trabalho descreve um estudo da absorção de água em dois diferentes tipos de polímeros expandidos (poliuretano e poliestireno expandido), em diferentes meios aquosos (água do mar e água destilada). Estudo sobre o efeito da geometria das amostras com relação à cinética de absorção de água demonstrou que as amostras com maior área de contato com a água se apresentam mais susceptíveis à absorção de água. Os estudos também revelaram que o poliuretano expandido sofreu uma importante perda de material devido ao seu manuseio durante os ensaios de absorção. A influência do meio aquoso foi também bastante notável para este material, no qual apresentou uma maior taxa de absorção nos ensaios com água destilada em comparação com os ensaios utilizando água do mar. Os resultados das análises demonstraram que o melhor material para ser utilizado como módulo de flutuabilidade do robô submarino é o poliestireno expandido, pois este material não apresentou uma notável degradação e perda de material durante os ensaios de absorção.
\end{abstract}

Palavras-chave: $R O V$, polímero expandido, absorção de água, degradação de materiais.

\section{Study of Expanded Polymers Water Absorption for Buoyancy Modulus Development of a Submarine Mini-robot}

\begin{abstract}
Owing to the low density and relative low price, expanded polymers appear to be competitive for buoyancy systems. Expanded polymers are particularly efficient to develop buoyancy modules of submarine robots such as ROV (Remote Operated Vehicle). This work describes water absorption mechanisms of two expanded polymers (expanded polyurethane and expanded polystyrene), in various aqueous media (seawater and distilled water). The influence of the samples geometry on the water absorption kinetics was studied. The samples with a larger contact area with water were found to be more susceptible to water absorption. The analyses also reveal a potential loss of material in the expanded polyurethane due to its manipulation during the absorption tests. The influence of the aqueous media was also significant for this material, which presents a level of absorption in distilled water higher than in seawater. The results of this study justify the selection of the expanded polystyrene, which appears particularly suitable to the development of the buoyancy modules of submarine mini-robots.
\end{abstract}

Keywords: ROV, expanded polymer, water absorption, materials degradation.

\section{Introdução}

Devido às dificuldades de condições de trabalho em ambientes subaquáticos, robôs submarinos do tipo ROV (Remote Operated Vehicle) estão sendo cada vez mais utilizados em diversas operações, substituindo as atividades que normalmente eram designadas a seres humanos. Tendo em vista que o homem pode trabalhar a uma máxima profundidade de $50 \mathrm{~m}$, estes veículos submarinos desempenham importantes tarefas na inspeção de equipamentos, canalizações, cabos submarinos e na exploração de petróleo em águas profundas (offshore) ${ }^{[1-3]}$, tais como, inspeções ambientais em rios e mares, propiciando monitoramento da biodiversidade através de câmeras, facilitando assim o estudo do meio subaquático.

Para compensar o peso da estrutura na água (chassi metálico ou de polímero) e dos vários equipamentos acoplados ao ROV (braço mecânico, sistemas de iluminação, câmera, cabos, etc.), um módulo de flutuabilidade é geralmente colocado na parte superior, promovendo assim a flutuação do robô submarino. Este módulo flutuante é feito de material de baixa densidade, com objetivo de neutralizar o máximo possível o peso do ROV na água, tendo em vista que ele deve também resistir às condições físico-químicas no meio ambiente que será aplicado (temperatura da água, condições do meio aquoso (água doce ou água do mar), efluentes, pressão, etc.). Por isso torna-se indispensável à realização de vários estudos preliminares visando à compreensão do comportamento dos materiais em várias condições de trabalho.

Os materiais utilizados para flutuabilidade dependem em grande parte da profundidade em que o ROV será submetido. Assim, para grandes profundidades, os materiais de flutuabilidade são geralmente espumas sintáticas, compostos de matriz de polímero reforçada com esferas vazias (de vidro, polímero ou compósitos). Em ambientes com menores profundidades, espumas de polímeros estão sendo aplicadas ${ }^{[2]}$. Visando a utilização dessas espumas de polímeros, este trabalho é focalizado sobre o estudo baseado em análises de absorção de água em dois diferentes tipos de polímeros expandidos: o poliuretano expandido (PU) e o poliestireno expandido (EPS). 
Estudos têm demonstrado que o transporte de substâncias através de um meio poroso, entre outros o transporte de moléculas de água, é governado por uma variedade de mecanismos físicoquímicos que dependem do fluxo da substância, da concentração local, das condições ambientais, da estrutura e dimensões dos poros, do nível de saturação do sistema de poros e da temperatura ${ }^{[4]}$. Estes mecanismos podem atuar simultaneamente, o que torna mais complexo o estudo e a definição de um modelo. Em um meio aquoso, sobre as condições físico-químicas de água do mar ou de água doce, por exemplo, as cinéticas de difusão podem ser modificadas pela degradação dos materiais polímeros que pode ocorrer durante o ensaio de absorção ${ }^{[4-7]}$. Neste sentido, o objetivo principal deste trabalho será de apresentar e comparar os resultados dos testes de absorção de água realizados sobre o PU e sobre o EPS, com relação as suas geometrias, meios aquosos de ensaios (água doce e água do mar), temperatura do meio ambiente, assim como o método experimental utilizado. Esses testes permitiram definir qual é o material mais adequado a ser utilizado na fabricação dos módulos de flutuabilidade que serão aplicados em um robô submarino do tipo ROV.

\section{Materiais e Métodos}

\section{Materiais}

Os materiais testados constituem-se de duas espumas de polímero: poliestireno expandido (EPS ou Isopor ${ }^{\circledR}$ ) de densidade $0,012 \pm 0,0003 \mathrm{~g} \cdot \mathrm{cm}^{-3}$, e poliuretano expandido (PU) de densidade $0,031 \pm 0,0064 \mathrm{~g} \cdot \mathrm{cm}^{-3}$.

O EPS é um plástico celular rígido, resultado da polimerização do estireno em água. $\mathrm{O}$ agente expansor para sua transformação é o pentano. O produto final é composto de pérolas de diâmetro médio $3,5 \mathrm{~mm}$. A Figura 1 mostra a fotomicrografia do EPS, na qual se podem observar os poros (região mais clara) e os espaços intersticiais (regiões mais escuras). A porosidade do material foi calculada a partir das densidades da espuma e do poliestireno compacto, no qual foi avaliada em torno de $98,8 \%$. As amostras foram cortadas em blocos de EPS a partir de um sistema de fio quente.

Para realizar a espuma de PU foi utilizado poliol poliéter, e difenilmetano diisocianato (MDI) polimérico. O processamento foi feito através da mistura do poliol com ciclopentano na proporção de 13,5 partes de pentano para 100 partes de poliol. Posteriormente a mistura com o MDI sob alta pressão em máquinas injetoras (150 bar). A relação entre a mistura de poliol com ciclopentano e MDI é 40 e 55\% respectivamente. Após injeção num recipiente aberto e um breve período de expansão, a mistura solidifica, constituindo-se de pequenas células que resultam em um material de baixa densidade com celas abertas. O diâmetro médio das células do PU expandido é em torno de $0,7 \mathrm{~mm}$. Ele foi avaliado a partir da observação microscópica do material (Figura 1). A porosidade do material foi calculada a partir das densidades da espuma e do poliuretano compacto, no qual foi avaliado em torno de $97,2 \%$ do material. Depois da polimerização, as amostras foram cortadas nas dimensões requeridas por meio de uma lâmina.

\section{Ensaios de absorção de água}

Nas condições de serviço, o flutuador será exposto a várias condições ambientais, tanto em condições de água doce como em condições de água do mar. Por isso se deve a importância da realização dos testes de absorção de água sobre os materiais testados em diversas condições físico-química do meio aquoso, com o intuito de se estudar as propriedades e as cinéticas de absorção de cada material.

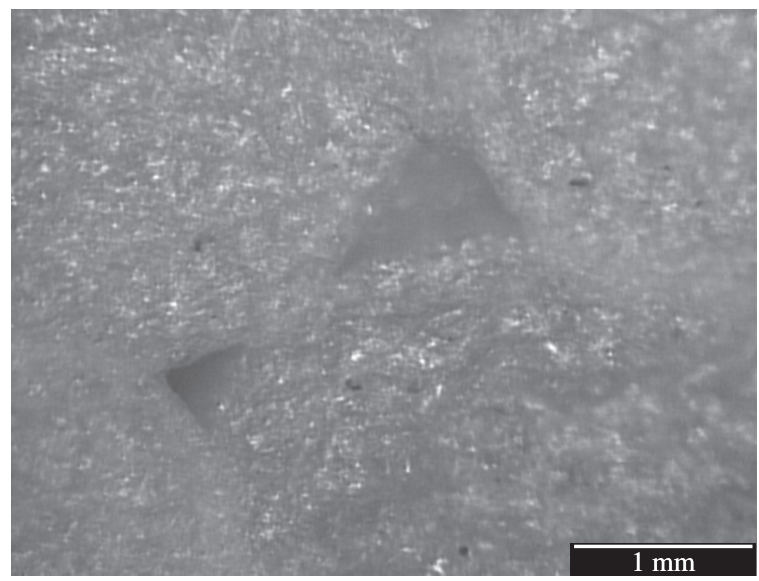

(a)



(b)

Figura 1. Fotografias obtidas por microscopia ótica $(\times 5)$. a) Poliestireno expandido (EPS) e b) Poliuretano expandido (PU).

\section{a) Método gravimétrico}

Para o estudo de absorção de água nos materiais foram aplicados os testes gravimétricos, por meio de um acompanhamento das evoluções das massas das amostras imergidas. Ao longo das realizações dos testes, o aumento da massa de cada amostra é calculado a partir da massa inicial da amostra $\left(m_{\text {inicial }}\right)$, com relação à massa da amostra medida no tempo $t\left(m_{\mathrm{t}}\right)$ (Equaçãa 1$)$ :

$$
\text { Aumento de massa }(\%)=100 \times \frac{m_{t}-m_{\text {inicial }}}{m_{\text {inicial }}}
$$

Essa massa de água absorvida no tempo $t$ é relacionada com a concentração de água presente dentro do material, conforme mostra a Equação 2:

$$
m_{t}=\int \underset{\text { espessura }}{\int c d x}
$$

em que:

- $m_{\mathrm{t}}$ : massa de água absorvida no tempo $t$;

- $c$ : concentração de água; e

- $d x$ : incremento de grade $x$.

Para normalizar as curvas, o aumento de massa é geralmente representado em função do parâmetro $\frac{\sqrt{t} \times S}{V}$.

Em que:

- $t$ : tempo do teste (dias);

- $S$ : superfície total da amostra $\left(\mathrm{mm}^{2}\right)$; e

- $V$ : volume total da amostra $\left(\mathrm{mm}^{3}\right)$. 


\section{b) Condições experimentais dos testes}

\section{Influência de diferentes meios aquosos}

Para estudar o efeito do meio ambiente sobre a cinética de difusão, os testes foram realizados em paralelo em dois diferentes meios aquosos: com água destilada (propriedades próximas da água doce) e com água do mar natural. As características da água do mar natural foram medidas com uma sonda oceanográfica - CTD que registra em contínuo a condutividade, a temperatura e a pressão, estas são apresentadas na Tabela 1 .

\section{Influência de diferentes geometrias das amostras}

Com objetivo de estudar o efeito da superfície do material em contato com a água com relação à cinética de difusão, duas geometrias foram testadas: placas de dimensões de $50 \times 50 \times 2 \mathrm{~mm}$ e cubos de dimensões de $20 \times 20 \times 20 \mathrm{~mm}$, sendo que os dois tipos de amostras se apresentaram com um volume comparável, mas com superfícies externas diferentes.

\section{Influência da temperatura}

Para estudar o efeito da temperatura sobre as cinéticas de difusão, os testes de absorção foram realizados com diferentes condições de temperatura. Esses testes foram realizados somente sobre o poliuretano, pois é o material que apresentou o comportamento mais complexo durante os ensaios. Assim, os testes com água destilada foram realizados nas temperaturas de 25 e $60{ }^{\circ} \mathrm{C}$, e os testes com água do mar foram realizados nas temperaturas de 5 e $25^{\circ} \mathrm{C}$.

\section{Influência do protocolo experimental}

Como objetivo validar o método experimental dos testes gravimétricos e avaliar a perda de material das amostras durante a manipulação, foram realizados testes sobre amostras de referência (teste em contínuo) e de sacrifício. Três amostras de referência foram testadas para cada condição de teste e manipuladas (medidas de peso e de dimensões) três vezes por semana. Em paralelo aos testes das amostras de referência, foram colocadas as amostras sacrificadas em repouso dentro da água, e foram retiradas ao longo do tempo (uma por semana, durante 12 semanas) a fim de avaliar o efeito de manuseio do material. Essas amostras foram pesadas no início dos testes e uma vez quando retiradas do meio aquoso.

Esses ensaios foram realizados com água destilada e com água do mar na temperatura ambiente (em torno de $25^{\circ} \mathrm{C}$ ). Essa temperatura em que os materiais foram submetidos durante os ensaios representa a temperatura máxima que pode ser observada na superfície da coluna d'água de um meio ambiente marinho ou fluvial.

Durante os ensaios de absorção, foram também realizadas as medidas de dimensões das amostras testadas a fim de se determinar se houve a perda ou aumento nas dimensões dos materiais.

Tabela 1. Características da água do mar coletada.

\begin{tabular}{ccccc}
\hline $\begin{array}{c}\text { Salinidade } \\
\left(\mathrm{g} . \mathrm{L}^{-1}\right)\end{array}$ & $\begin{array}{c}\text { Temperatura de } \\
\text { coleta }\left({ }^{\circ} \mathbf{C}\right)\end{array}$ & $\begin{array}{c}\text { Oxigeno } \\
\left(\mathbf{m L} . \mathbf{L}^{-1}\right)\end{array}$ & $\begin{array}{c}\text { Densidade } \\
\left(\mathbf{g . c m}^{-3}\right)\end{array}$ & $\mathbf{p H}$ \\
\hline 36,72 & 28,6 & 106,71 & 1,0235 & 8 \\
\hline
\end{tabular}

Depois dos testes de absorção, as amostras testadas foram colocadas em uma estufa para secagem. A comparação das massas secas das amostras medidas antes e depois dos testes permitiu avaliar a perda de material que ocorreu no meio aquoso durante os ensaios.

Maiores detalhes sobre as amostras testadas, referente as condições de temperatura dos testes e a finalidade dos testes são resumidas na Tabela 2. A montagem dos testes é representada na Figura 2.

Para cada condição de teste, três amostras de cada geometria (placa e cubo) foram testadas com a finalidade de estudar a repetibilidade das medidas. Para simplificar a leitura dos gráficos, somente a média e desvio padrão das medidas são representadas.

c) Determinação do coeficiente de difusão e da energia de ativação

Para determinar o coeficiente de difusão do processo de absorção de água nos materiais, foi considerado o processo de difusão seguindo o modelo de Fick ${ }^{[8]}$. Devido às dimensões das amostras serem em forma de placa fina (relação entre comprimento e espessura), a difusão pode ser considerada como sendo uniaxial. Neste caso, a curva de difusão obtida por ensaio gravimétrico permite atingir o coeficiente de difusão $D$. A parte inicial da curva de absorção no modelo de Fick é linear e a equação da linha pode ser calculada a partir da Equação 3:

$$
\frac{m_{t}}{m_{0}}=\frac{m_{\infty}}{m_{0}} \times \frac{4}{h} \sqrt{\frac{D t}{\pi}}
$$

em que:

- $m_{0}$ : a massa inicial do material (no tempo $t=0$ );

- $m_{\mathrm{t}}$ : a massa do material no tempo $t$;

- $m_{\infty}$ : a massa do material no grau de saturação; e

- $h$ : a espessura da amostra.
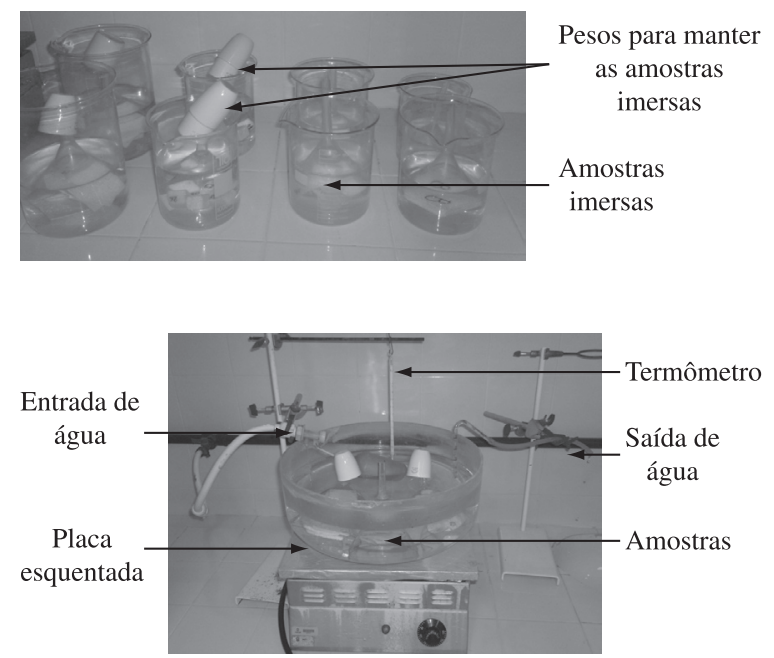

Figura 2. Montagem dos testes de absorção de água. a) A temperatura ambiente (em torno de $25{ }^{\circ} \mathrm{C}$ ) e b) a $60{ }^{\circ} \mathrm{C}$.

Tabela 2. Resumo das condições dos testes de absorção.

\begin{tabular}{ccccc}
\hline $\begin{array}{c}\text { Dimensões das } \\
\text { amostras }\left(\mathbf{m m}^{3}\right)\end{array}$ & $\begin{array}{c}\text { Temperatura } \\
\text { dos testes }\end{array}$ & $\begin{array}{c}\text { Meio de } \\
\text { teste }\end{array}$ & $\begin{array}{c}\text { Duração dos } \\
\text { testes }\end{array}$ & Objetivo do teste \\
\hline $50 \times 50 \times 2$ (placas) & 25 e $60^{\circ} \mathrm{C}$ & Água destilada & 12 semanas & Determinação das cinéticas de absorção de água \\
$20 \times 20 \times 20$ (cubos) & 5 e $25^{\circ} \mathrm{C}$ & Água do mar & 12 semanas & $\begin{array}{c}\text { Determinação das cinéticas de absorção de água } \\
\text { Amostras de "sacrifício" } \\
\text { ・ determinação das cinéticas "reais" de absorção de água } \\
\text { ・ determinação da degradação/perda de materiais durante } \\
\text { os ensaios de absorção }\end{array}$ \\
\hline
\end{tabular}


O coeficiente de difusão geralmente aumenta com a elevação da temperatura do meio e esta relação pode ser descrita por meio da equação de Arrhenius (Equação 4):

$$
D=D_{0} \times \exp \left(\frac{-E a}{R T}\right)
$$

em que:

- $\quad D$ : fator pré-exponencial $\left(\mathrm{m}^{2} . \mathrm{s}^{-1}\right)$;

- Ea: energia de ativação $\left(\mathrm{J} \cdot \mathrm{mol}^{-1}\right)$;

- $R$ : constante universal dos gases $\left(=8,134 \mathrm{~J} \cdot \mathrm{mol}^{-1} \cdot \mathrm{K}^{-1}\right)$; e

- $T$ : temperatura $(\mathrm{K})$.

Assim, para cada condição de teste, foi determinado o coeficiente de difusão $D$, e no caso dos ensaios com várias temperaturas, foi também determinada a energia de ativação $E a$ do processo de difusão.

\section{Resultados e Discussão}

\section{Efeito da geometria}

A Figura 3 apresenta a comparação entre as cinéticas de absorção nas amostras em forma de placas e nas amostras em forma de cubos, em contato com água destilada na temperatura em torno de $25^{\circ} \mathrm{C}$.

As curvas de absorção obtidas nas amostras em forma de placas e nas amostras em forma de cubos se apresentaram sobrepostas. Levando em consideração o mesmo tempo de ensaio, foi registrada uma menor absorção de água nas amostras em forma de cubos do que nas amostras em forma de placas. Pois os resultados demonstram que as amostras com maior área de contato com a água,


Figura 3. Efeito da geometria sobre as cinéticas de absorção - testes na água destilada $\left(1 \mathrm{bar} / 25^{\circ} \mathrm{C}\right)$. se apresentam mais susceptíveis a absorção de água. Isso determinou a acentuar o interesse de realizar os testes de absorção com placas finas, no sentido de acelerar o processo de difusão e obter a cinética de absorção mais rapidamente.

\section{Efeito da temperatura}

A Figura 4 apresenta o efeito da temperatura sobre as cinéticas de absorção das placas finas de PU com dimensões de $50 \times 50 \times 2 \mathrm{~mm}$ durante os ensaios com água destilada (Figura 4a) e durante os ensaios com água do mar (Figura 4b).

Os resultados das amostras que se encontravam em contato com água destilada na temperatura de 25 e $60{ }^{\circ} \mathrm{C}$ (Figura 4a), demonstraram que a absorção de água tende acelerar com o aumento da temperatura, como já foi observado em vários estudos realizados sobre polímeros ${ }^{[9,10]}$. Isto demonstrou que a cinética de absorção é altamente influenciada pela temperatura.

No caso das amostras testadas com água do mar, não se observou uma diferencia notável nas cinéticas de absorção em relação às temperaturas dos testes. O gráfico da Figura $4 \mathrm{~b}$ demonstra uma ligeira queda na cinética durante os ensaios realizados na temperatura de $25^{\circ} \mathrm{C}$, que provavelmente ocorre devido a uma degradação e perda de material no meio aquoso.

\section{Correções das curvas de absorção}

As cinéticas de absorção de água nas amostras de referência e nas amostras sacrificadas, obtidas durante os ensaios realizados com água destilada, são apresentadas na Figura 5.

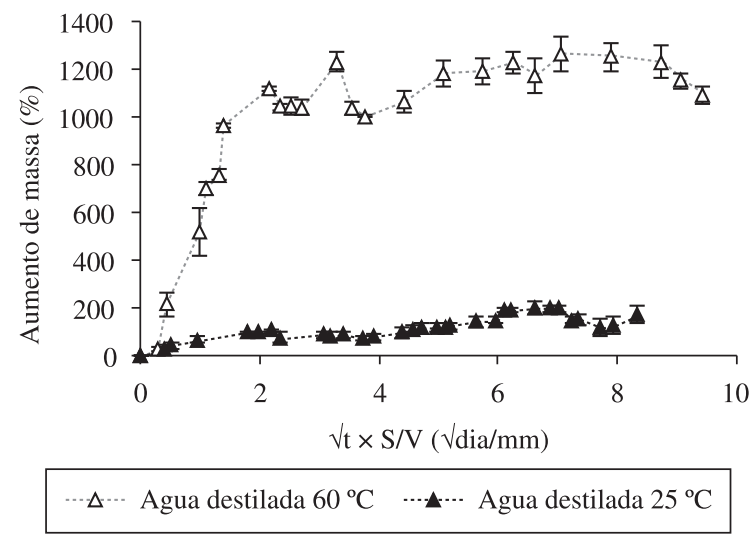

(a)

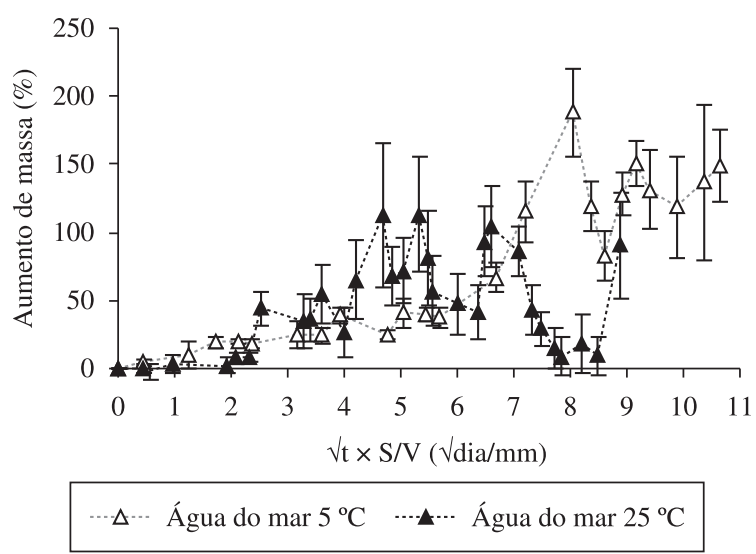

(b)

Figura 4. Efeito da temperatura sobre as cinéticas de absorção (placas de PU de espessura: $2 \mathrm{~mm}$ ). a) Água destilada: 25 e $60^{\circ} \mathrm{C}$ e b) água do mar: 5 e $25^{\circ} \mathrm{C}$. 




(a)

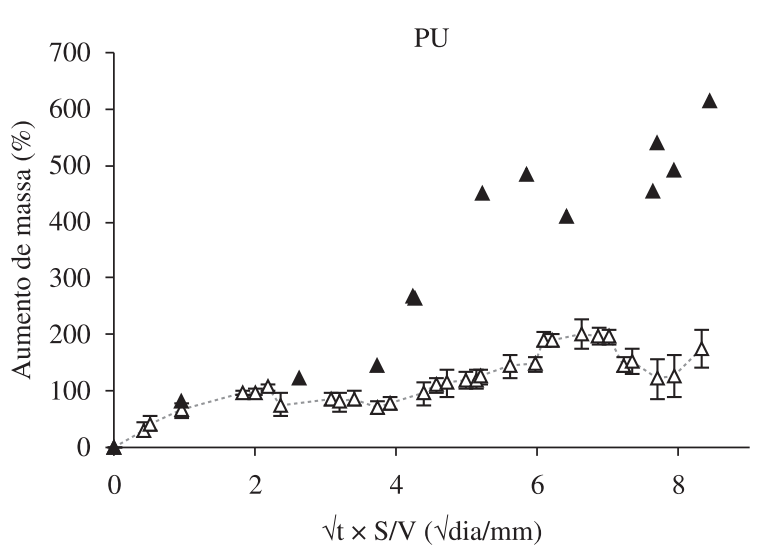

(b)

$\Delta$ Teste contínuo $\Delta$ Amostra "sacrificada"

Figura 5. Comparação das cinéticas de absorção de água das amostras testadas em contínuo e "sacrificadas" - testes na água destilada $\left(1 \mathrm{bar} / 25^{\circ} \mathrm{C}\right)$. a) EPS e b) PU.

No caso do EPS, a absorção nas amostras de referência e a absorção nas amostras sacrificadas são comparáveis, sendo que o EPS se apresentou no final com uma taxa de absorção abaixo de $180 \%$. As cinéticas de absorção do EPS se apresentaram na primeira fase com um aumento de massa em torno de $50 \%$ em relação à massa inicial, o que provavelmente está relacionado a uma difusão superficial (difusão de moléculas na fase da superfície) e a uma difusão das moléculas nos interstícios entre os poros do material. Depois a massa de água absorvida continua a aumentar quase linearmente até o fim dos ensaios, o que pode estar relacionado a uma difusão interna, ou seja, dentro dos poros.

No caso do PU, a absorção de água nas amostras sacrificadas é maior e mais rápida que nas amostras de referência. A diferencia observada nas cinéticas de absorção está diretamente ligada a uma perda de material das amostras de referência. Essa perda ocorreu durante os testes em contínuo, devido ao manuseio das amostras, isso explicaria as diferenças observadas nas medidas gravimétricas (Figura 5). Esses resultados justificam a importância dos testes com amostras sacrificadas, no sentido de obter o nível de absorção de água mais próximo da realidade.

Para ilustrar a perda de material que ocorreu durante os ensaios realizados em contínuo, foram realizadas medidas antes e depois dos testes de absorção das massas secas das amostras de EPS e de PU (sacrifício e referência). Os resultados obtidos são apresentados na Figura 6.

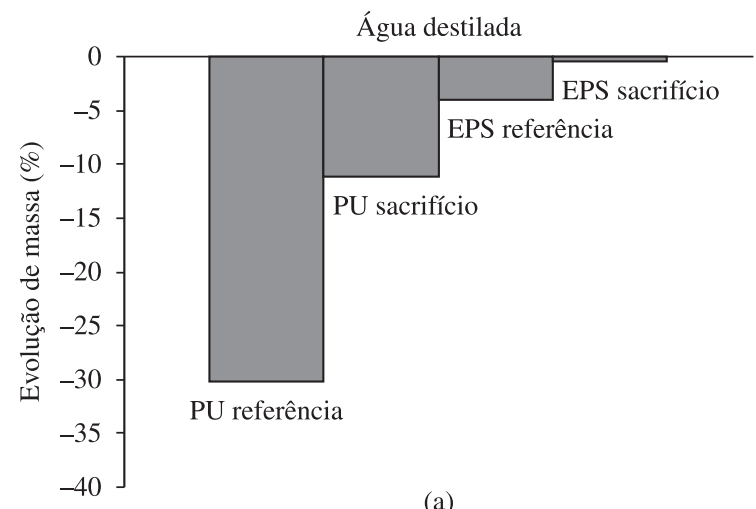

(a)



(b)

Figura 6. Diferencia de massa seca das amostras de poliuretano antes e depois dos testes de absorção. a) Com água destilada e b) com água do mar.

Os resultados demonstram que no caso do EPS, as amostras de referência não sofreram uma perda de material significativa durante os testes com água destilada (Figura 6a) e com água do mar (Figura 6b), pois as perdas de massa seca não ultrapassem $4 \%$.

No caso do PU, as amostras de referência sofreram uma perda de material bastante significativa durante os testes, devido ao manuseio: em torno de $30 \%$ de perda de massa na água destilada (Figura 6a) e $35 \%$ de perda de massa na água do mar (Figura 6b). No caso das amostras de sacrifico, a perda de massa do material foi medida em torno de $10 \%$ nas amostras testadas com água doce (Figura 6a) e $13 \%$ nas amostras testadas com água do mar (Figura 6b), no qual demonstra uma notável limitação da perda de material quando a amostra não é manipulada.

O fenômeno de degradação e perda de material das amostras de PU durante o manuseio também pode ser ilustrado na Figura 7, que apresenta a evolução das espessuras nas placas de PU e de EPS, durante os testes de absorção realizados com água destilada.

Os resultados demonstraram que as espessuras das placas de PU diminuem significativamente (até $9 \%$ em comparação com as espessuras iniciais) e as espessuras das placas de EPS não apresentaram uma diminuição notável quando comparadas com as placas de PU.

As cinéticas de absorção das amostras de sacrifício de PU demonstraram que durante a primeira fase ocorre um aumento de massa em torno de $120 \%$ em relação a massa inicial, ocorrendo provavelmente uma difusão na superfície das amostras. Na segunda fase ocorre um aumento de massa ainda mais rápido, provavelmente relacionado a uma difusão nas células abertas do PU (Figura 7).

\section{Efeito do meio aquoso}

A Figura 8 ilustra a comparação dos níveis de absorção de água obtidos nas amostras de referência e nas amostras de sacrifício, durante 12 semanas de ensaios, com água destilada e com água do mar. 
No caso do EPS os ensaios demonstram que as cinéticas de absorção se apresentaram comparáveis nos dois tipos de meios aquosos (água destilada e água do mar), tanto nos testes das amostras de referência como nos testes das amostras de sacrifício. Nos dois casos houve um aumento mássico de aproximadamente $160 \%$, depois das doze semanas de ensaios (Figura 8a).

No caso do PU, a importância do meio aquoso (água destilada e água do mar) sobre as cinéticas de absorção se apresentou bastante significativa. Nos testes realizados com as amostras sacrificadas a curva de absorção obtida com água destilada se apresentou acima da curva de absorção obtida nos testes com água do mar. Depois de doze semanas de teste, o aumento de massa das amostras de PU atingiu $600 \%$ nos testes realizados com água destilada, contra $300 \%$ nos testes realizados com água do mar (Figura 8b).

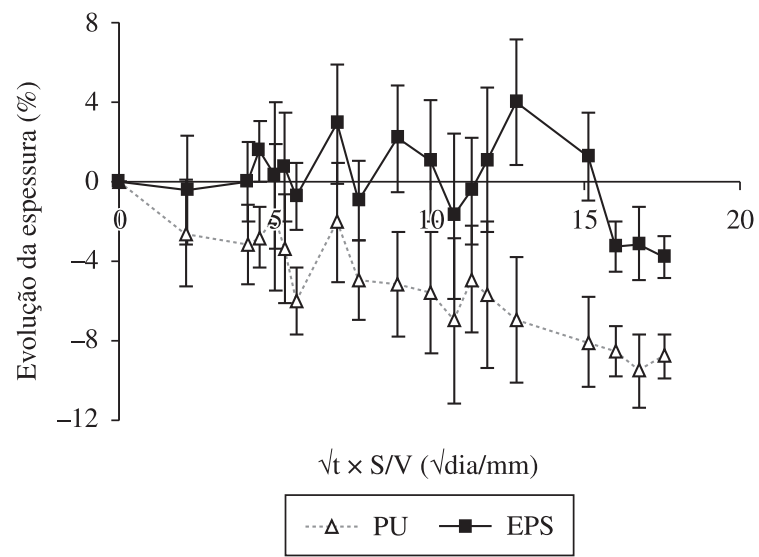

Figura 7. Evolução de espessura das placas de PU e de EPS durante os testes de absorção na água destilada (medida no centro das placas).

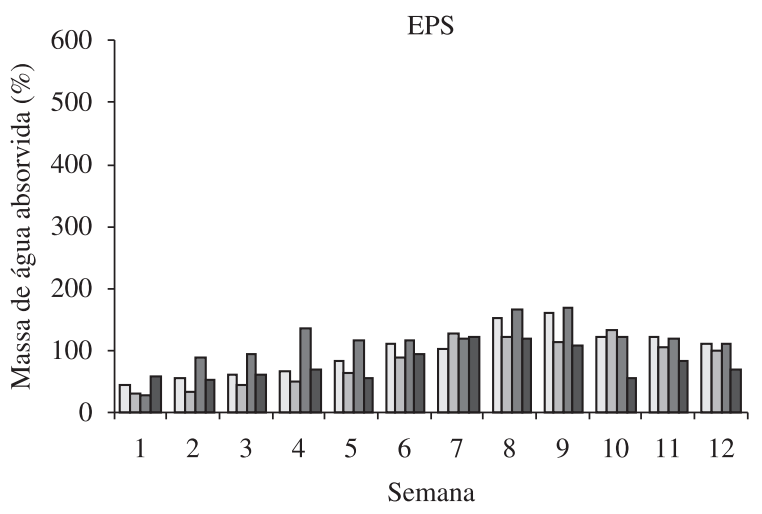

(a)
Essa diferencia nas curvas de absorção deve estar provavelmente ligada a dois fatores principais:

- De um lado, o PU expandido pode sofrer uma maior degradação e perda de material em contato com a água do mar, devido à agressão do meio marinho e a provável ruptura de ligações químicas devido à ação da água salgada ${ }^{[6,7,10]}$. Na Figura 6, a comparação entre as massas secas, medidas antes e depois dos testes de absorção demonstra uma diferença de aproximadamente $5 \%$ entre as amostras testadas com água doce e as amostras testadas com água do mar. Isso representa uma maior perda de material no meio marinho (água do mar), o que pode conduzir a explicar a diferença observada nos testes com água destilada.

- Uma segunda explicação provável para justificar a diferença nos diferentes meios aquosos, pode estar relacionada ao seguinte fator: no caso do meio aquoso marinho, há uma grande concentração de sais dissolvidos, sendo em maior quantidade o cloreto de sódio, que pode atuar na interface do material, fato que não ocorre de modo similar no sistema com água destilada ${ }^{[11]}$.

\section{Determinação do coeficiente de difusão e da energia de ativação}

Para cada perfil de absorção, o coeficiente de difusão foi determinado a partir do modelo descrito no parágrafo 2.2.c. No caso do PU, os testes de absorção foram realizados com várias temperaturas $\left(25\right.$ e $60{ }^{\circ} \mathrm{C}$ na água destilada e 5 e $25^{\circ} \mathrm{C}$ na água do mar), neste caso foi também determinada a energia de ativação do processo de difusão. Os resultados são resumidos na Tabela 3.

Os resultados apresentados na Tabela 3 demonstram que o coeficiente de difusão tende a aumentar com o aumento da temperatura. No caso do PU testado com água destilada, o coeficiente de difusão $D$ passa de $4 \times 10^{-3} \mathrm{~m}^{2} \cdot \mathrm{s}^{-1}$ na temperatura de $25^{\circ} \mathrm{C}$ para $15 \times 10^{-3} \mathrm{~m}^{2} \cdot \mathrm{s}^{-1}$ na temperatura de $60{ }^{\circ} \mathrm{C}$. Na água do mar, $D$ passa

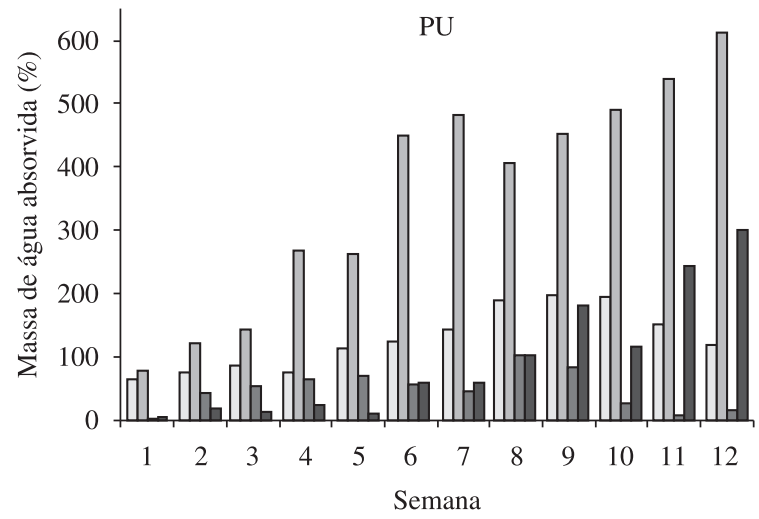

(b)

$$
\begin{array}{ll}
\square \text { Placas de referência_água destilada } & \square \text { Placas de referência_água do mar } \\
\square \text { Placas sacrificadas_água destilada } & \square \text { Placas sacrificadas_água do mar }
\end{array}
$$

Figura 8. Comparação do nível de absorção de água das amostras testadas em contínuo e "sacrificadas" para cada semana de teste. a) EPS e b) PU.

\begin{tabular}{|c|c|c|c|c|c|c|}
\hline \multirow[t]{2}{*}{ Material } & \multirow{2}{*}{$\begin{array}{l}\text { Temperatura do } \\
\text { ensaio }\left({ }^{\circ} \mathbf{C}\right)\end{array}$} & \multicolumn{2}{|c|}{ Meio aquoso } & \multirow[t]{2}{*}{$\mathrm{D}_{0}\left(\mathrm{~m}^{2} \cdot \mathrm{s}^{-1}\right)$} & \multirow[t]{2}{*}{ Ea $\left(J^{\prime} \mathbf{m o l}^{-1}\right)$} & \multirow[t]{2}{*}{ D $\left(\mathrm{m}^{2} \cdot \mathrm{s}^{-1}\right)$} \\
\hline & & Água destilada & Água do mar & & & \\
\hline \multirow[t]{4}{*}{$\mathrm{PU}$} & 25 & $x$ & & 0,057 & 11,15 & $3,91 \times 10^{-3}$ \\
\hline & 60 & $x$ & & & & $14,95 \times 10^{-3}$ \\
\hline & 5 & & $x$ & $9,91 \times 10^{-5}$ & 13,18 & $0,48 \times 10^{-3}$ \\
\hline & 25 & & $x$ & & & $2,36 \times 10^{-3}$ \\
\hline \multirow[t]{2}{*}{ EPS } & 25 & $x$ & & - & - & $0,93 \times 10^{-3}$ \\
\hline & 25 & & $x$ & - & - & $2,32 \times 10^{-3}$ \\
\hline
\end{tabular}

Tabela 3. Resultados dos cálculos do coeficiente de difusão e da energia de ativação (testes de absorção realizados em contínuo). 
de $0,5 \times 10^{-3} \mathrm{~m}^{2} \cdot \mathrm{s}^{-1}$ na temperatura de $5{ }^{\circ} \mathrm{C}$ para $2,4 \times 10^{-3} \mathrm{~m}^{2} \cdot \mathrm{s}^{-1}$ na temperatura de $25^{\circ} \mathrm{C}$. No caso do EPS com água doce, o coeficiente de difusão foi calculado em torno de $1 \times 10^{-3} \mathrm{~m}^{2} \cdot \mathrm{s}^{-1}$ na temperatura de $25^{\circ} \mathrm{C}$, e com água do mar foi calculado em torno de $2,3 \times 10^{-3} \mathrm{~m}^{2} \cdot \mathrm{s}^{-1}$ com o mesmo valor de temperatura. Comparando os valores obtidos pelo PU nas mesmas condições, os valores calculados para o EPS se encontraram ligeiramente inferiores.

\section{Conclusões}

Neste trabalho foram apresentados e discutidos vários testes de absorção de água realizados sobre dois polímeros expandidos (PU e EPS), a fim de avaliar as propriedades de absorção de cada material e determinar qual deles será aplicado no modulo de flutuabilidade do robô submarino do tipo ROV.

Nos testes realizados para se estudar o efeito da geometria das amostras com relação à cinética de absorção de água, verificou se que nas amostras em forma de placa se obteve uma absorção de água mais rápida que nos cubos. Isso justificou o interesse em testar amostras em forma de placa fina, pois estas se apresentaram com uma maior superfície de contato com a água, no qual tenderam a acelerar as cinéticas de difusão e reduzir os tempos de ensaios.

Nos testes realizados com várias temperaturas, observou-se que ocorreu um aumento de absorção de água com o aumento da temperatura. Os cálculos de coeficiente de difusão e de energia de ativação confirmaram também esses resultados.

Para avaliar a degradação dos materiais durante os ensaios, testes de amostras complementares chamadas de "sacrifício" foram realizados. Os resultados demonstraram que não foram registradas notáveis diferenças nos perfis de absorção entre as duas condições de ensaios (sacrifício e continuo) nas amostras de EPS. Além disso, foi registrada uma menor absorção de água nas amostras de EPS em comparação com as amostras de PU. No caso do PU, o material apresentou cinéticas de absorção bastante diferentes entre as amostras testadas em contínuo com relação às amostras de sacrifício. Essa diferencia se deve a uma perda de material devido ao manuseio durante os ensaios em contínuo. A degradação do PU foi ilustrada através do registro da diminuição da espessura das amostras e através da comparação das massas secas medidas antes e depois dos testes.

Os testes realizados nos dois diferentes meios aquosos (água destilada e água do mar) demonstraram que as amostras de EPS se apresentaram com cinéticas de absorção comparáveis. Nas amostras de PU, a cinética de absorção foi mais elevada e mais rápida na água destilada do que na água do mar. Essa diferencia se deve provavelmente a dois principais fatores:

- Degradação do PU através da ruptura de ligações químicas em contato com a água salgada, favorecendo uma perda de material durante os ensaios;

- Presença de uma grande concentração de sais dissolvidos na água do mar, sendo em maior quantidade o cloreto de sódio, que pode atuar na interface do material e limitar o fenômeno de absorção de água no material.

A partir dos resultados de absorção apresentados neste trabalho chegou à conclusão que o EPS se apresentou como o material mais adequado para ser aplicado em módulos de flutuabilidade do robô submarino. Pois este material apresentou uma taxa de absorção menor e também uma menor degradação nos meios aquosos em comparação ao PU.

É importante salientar que para realizar flutuador que resiste pressão hidrostática de aproximadamente 10 bar (profundidade de 100 m), serão necessários a realização de novos testes (absorção e compressão) com revestimentos de proteção.

\section{Agradecimentos}

$\mathrm{O}$ primeiro autor agradece à FUNCAP/CNPq pela concessão da Bolsa de Pesquisa. Os autores agradecem os auxílios financeiros obtidos pela FINEP e pelo Banco do Nordeste (projeto SAMBA). A Antônio Wellington Cavalcante Lobo do Laboratório da Química da UNIFOR pela sua ajuda durante os ensaios e as empresas Esmaltec e Isoplast pelo fornecimento dos materiais.

\section{Referências Bibliográficas}

1. Fossen, T. I. - "Guidance and Control of Ocean Vehicles", John Wiley \& Sons Ltd, (1994)

2. Christ, R. D. \& Wernli Sr, R. L. - "The ROV manual: a user guide for observation-class Remotely Operated Vehicle", Elsevier Ltd., (2007).

3. Last, G. \& Williams, P. - "An introduction to ROV operations", OPL publisher, (1992).

4. Sonnenschein, M.; Wendt, B. L.; Schrock, A. K.; Sonney, J. M. \& Ryan, A. J. - "The relationship between polyurethane foam microstructure and foam aging". Polymer, 49, p. 934-942 (2008).

5. Boubakri, A.; Elleuch, K.; Guermazi, N. \& Ayedi, H. F. - "Investigations on hygrothermal aging of thermoplastic polyurethane material". Materials and Design, 30, p. 3958-3965 (2009).

6. Crank, J. J. \& Park, G. S. - "Diffusion in Polymers", Academic Press, London, New York (1968)

7. Li, X. \& Weitsman, J. - "Sea-water effects on foam-cored composite sandwich lay-ups". Composites: Part B, 35, p.451-459 (2004).

8. Rutkowska, M.; Krasowska, K.; Heimowska, A.; Steinka, I. \& Janik, H. - "Degradation of polyurethanes in sea water". Polymer Degradation and Stability, 76, p. 233-239 (2002).

9. Whitaker, G.; Darby, M. I.; Wostenholm, G. H.; Yates, B.; Collins, M. H.; Lyle, A. R. \& Brown, B. - "Influence of temperature and hydrostatic pressure on moisture absorption in polymer resins". Journal of Materials Science, 26, p. 49-55 (1991).

10. Davies, P. \& Evrard, G. - "Accelerated ageing of polyurethanes for marine applications". Polymer Degradation and Stability, 92, p.1455-1464 (2007).

11. Tanobe, V. O. A.; Sydenstricker, T. H. D.; Amico, S. C.; Vargas, J. V. C. \& Zawadzki, S. F. - "Evaluation of Flexible Polyurethane Foams Modified Through Polystyrene Grafting a Sorbent Material for Oil Spills". Journal of Applied Polymer Science (2008).

Enviado: 10/07/09

Reenviado: $26 / 01 / 10$

Aceito: $22 / 02 / 10$

DOI: $10.1590 /$ S0104-14282010005000032 